\title{
Mortality and Clostridium difficile infection: a review
}

Brett G Mitchell ${ }^{1 *}$ and Anne Gardner ${ }^{1,2}$

\begin{abstract}
Background: Clostridium difficile infection (CDI) is a common cause of diarrhoea in hospitalised patients. Around the world, the incidence and severity of CDI appears to be increasing, particularly in the northern hemisphere. The purpose of this integrative review was to investigate and describe mortality in hospitalised patients with CDI.

Methods: A search of the literature between 1 January 2005 and 30 April 2011 focusing on mortality and CDI in hospitalised patients was conducted using electronic databases. Papers were reviewed and analysed individually and themes were combined using integrative methods.

Results: All cause mortality at 30 days varied from $9 \%$ to 38\%. Three studies report attributable mortality at 30 days, varying from $5.7 \%$ to $6.9 \%$. In hospital mortality ranged from $8 \%$ to $37.2 \%$

Conclusion: All cause 30 day mortality appeared to be high, with 15 studies indicating a mortality of $15 \%$ or greater. Findings support the notion that CDI is a serious infection and measures to prevent and control CDI are needed. Future studies investigating the mortality of CDI in settings outside of Europe and North America are needed. Similarly, future studies should include data on patient co-morbidities.
\end{abstract}

Keywords: Clostridium difficile infection, Clostridium difficile associated diarrhoea, Mortality, Death

\section{Background}

The spectrum of diseases caused by Clostridium difficile ranges from uncomplicated diarrhoea to pseudomembranous colitis and toxic megacolon, and is often termed 'Clostridium difficile-associated diarrhoea' or 'Clostridium difficile infection' (CDI) [1-4]. Around the world, the incidence and severity of CDI has increased, particularly in the northern hemisphere [5]. This increase appears to be driven by a number of factors, including large outbreaks of CDI in hospitals, a change in circulating strains of $C$. difficile, and factors such as inappropriate antibiotic usage and poor standards of environmental cleanliness [6-10]. This paper presents a review of studies that have investigated mortality and CDI in hospitalised patients.

\section{Methods}

\section{Design}

An integrative review design was used. An integrative design was chosen because it summarises empirical and

\footnotetext{
* Correspondence: bgmitc001@myacu.edu.au

${ }^{1}$ School of Nursing, Midwifery and Paramedicine, Australian Catholic University, DicksonPO BOX 256, ACT, Australia

Full list of author information is available at the end of the article
}

theoretical literature and allows for the synthesis of results when study designs and methodologies vary between studies. As a result, it provides a more comprehensive understanding of a particular issue [11].

\section{Search Methods}

The literature was accessed through searches on two electronic databases-Medline and Pubmed-limited to the period 1 January 2005 to 30 April 2011. This limitation reflects the recently changing epidemiology of CDI. Other limits included only searching literature published in English, and studies involving humans. Key search words used were 'Clostridium difficile and mortality' and 'Clostridium difficile and death'. These searches were combined, with duplicate studies removed.

The next step of the search strategy process involved a preliminary review of the articles. Only prospective or retrospective articles that were case controlled, cohort or reviews were included. Additionally, articles were only included if they examined the mortality of hospitalised patients and were not limited to CDI in a specific patient group, for example, a person with cancer. Only articles

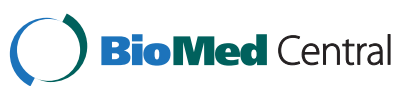


that did not use CDI as a comparison group were included, for example, mild versus severe CDI and related mortality. The rationale for excluding such articles was to gain a better understanding of CDI in the general hospitalised population rather than those with a specific illness.

A second review of the articles was undertaken, and this step excluded articles that did not examine mortality at fixed intervals, for example, 30 or 90 days. The inclusion of studies that documented mortality at fixed intervals was chosen in an attempt to assist the pooling of data during data analysis.

\section{Search Outcome}

The initial search yielded 362 articles. Following the first review, 303 articles were excluded and 59 articles remained. The second review, which excluded articles that did not examine CDI mortality at fixed intervals, resulted in a further exclusion of 23 articles. A total of 26 articles remained after the second review. Figure 1 provides a summary of the search strategy process.

\section{Quality Appraisal}

All papers included in this review were published in peer-reviewed journals.

\section{Data abstraction and synthesis}

All articles were analysed sequentially. The author, year, purpose, study design, data collection and analysis were reviewed. Data on mortality at fixed intervals were extracted from the studies and a table was populated (see Table 1).

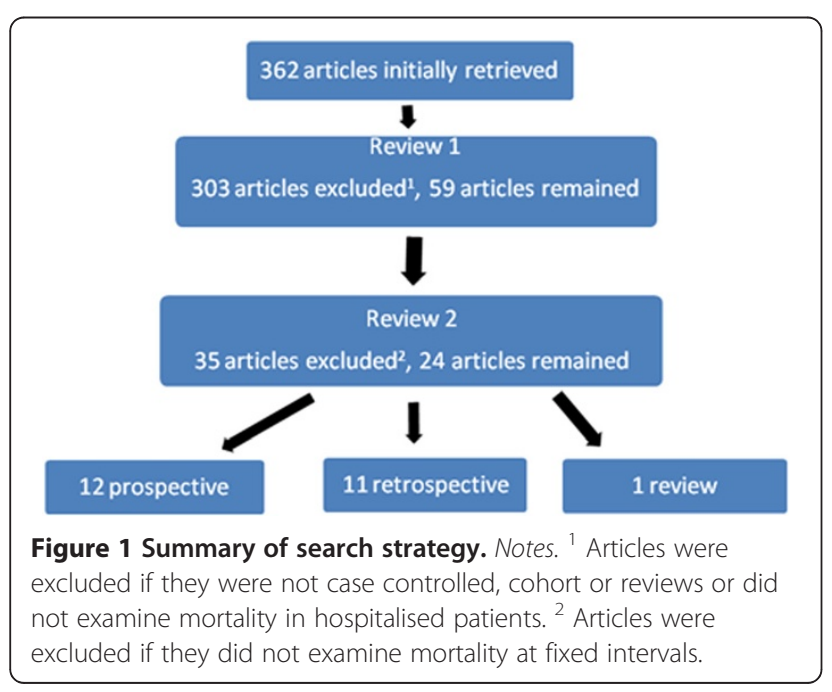

\section{Results}

\section{Study Characteristics}

Of the 24 articles included, 12 were prospective, 11 retrospective and one was a review. Eighteen studies reported mortality at 30 days or less, with 12 studies reporting mortality at further endpoints, predominantly 90 or 180 days. One study that reported 30-day mortality used 30-day post-discharge as the definition [12]. The choice of 30 days post-discharge as the method used to examine mortality was made due to limitations in available data, which should be noted when considering results from this study. Four studies examined in-hospital mortality in addition to 30-day mortality. The reported mortality in each of these studies is detailed in Table 1 and is explored in more detail later.

The search strategy used to identify articles for this review did not identify the same articles in the review published by Karas, Enoch \& Aliyu (2010). Seven articles included in the review by Karas, Enoch and Aliyu [13] were not include in our review. These studies did not meet our inclusion criteria and were excluded if the participants were from a selected group. For example, they had a specific strain of CDI or had severe CDI. Conversely, our study did identify and included 14 studies not used by Karas, Enoch and Aliyu [13]. The primary reason for this discrepancy was the recent publications of studies, with 11 of these 14 published in the past two years. The review by Karas, Enoch and Aliyu [13], also focussed on attributable mortality.

\section{Reported mortality}

As reported in the included studies, mortality varied considerably, both in the type of mortality calculated and the figures represented. The study design, exclusion criteria of participants and the data collected in the studies varied, making the pooling of data for analysis impossible. All-cause mortality at 30 days varied from $9 \%$ to $38 \%$, as shown in Table 1 . Three studies reported allcause mortality at 90 days, with a range of $27 \%$ to $30 \%$ [14-16]. Similarly, three studies report attributable mortality at 30 days, varying from $5.7 \%$ to $6.9 \%$ [17-19]. Inhospital mortality was reported in four studies and ranged from $8 \%$ to $37 \%$ [20-23].

Eighteen studies documented all-cause mortality at 30 days, or 28 days in the case of the study undertaken by Sundram et al. [24], which examined two strains of C.difficile (027 and 106) and their respective mortality. The total cohort size was larger than the two groups combined; therefore, it was unclear whether participants with other strains of C.difficile died. Acknowledging the limitations of different study designs, and excluding the study undertaken by Sundram et al. [24], 2,041 of 7,774 persons (26.3\%) died within 30 days of CDI diagnosis. These figures include people identified with CDI in these studies 
Table 1 Summary of reported mortality from literature

\begin{tabular}{|c|c|c|c|c|c|}
\hline Author & Study type & Country & 30-day mortality & $\begin{array}{l}\text { Mortality at } \\
\text { endpoint (other) }\end{array}$ & Participants \\
\hline $\begin{array}{l}\text { Arvand, Hauri, Zaiss, Witte } \\
\text { \& Bettge-Weller (2009) }\end{array}$ & $\begin{array}{l}\text { Prospective } \\
\text { multicentre }\end{array}$ & Germany & $25 \%$ & - & 41 \\
\hline $\begin{array}{l}\text { Bhangu, Bhangu, Nightingale } \\
\text { \& Michael (2010) }\end{array}$ & Cohort & UK & $38 \%$ & - & 158 \\
\hline \multirow{2}{*}{$\begin{array}{l}\text { Bishara, Peled, Pitlik } \\
\& \text { Samra (2008) }\end{array}$} & Case control & Israel & $15 \%$ case & - & Total 217 \\
\hline & & & $11.5 \%$ control (NS) & & 52 cases \\
\hline Cadena et al. (2010) & Cohort & US & $16 \%$ & $29 \%$ at 90 days & 129 \\
\hline Chung et al. (2010) & Cohort & Taiwan & $23.3 \%$ & $37.2 \% \mathrm{IHM}$ & 86 \\
\hline $\begin{array}{l}\text { Cloud, Noddin, Pressman, } \\
\text { Hu \& Kelly (2009) }\end{array}$ & Cohort & US & - & $12.1 \% \mathrm{IHM}$ & 272 \\
\hline \multirow[t]{2}{*}{ Dubberke et al. (2008) } & Case control & US & - & $\begin{array}{l}38 \% \text { cases } \\
\text { at } 180 \text { days }\end{array}$ & $\begin{array}{l}\text { Cohort = } \\
18,050390 \\
\text { cases }\end{array}$ \\
\hline & & & & $\begin{array}{l}12 \% \text { non-cases } \\
\text { at } 180 \text { days }\end{array}$ & \\
\hline Fenner et al. (2008) & Cohort & & Switzerland & $9 \%$ & - \\
\hline \multicolumn{6}{|l|}{78 cases } \\
\hline \multirow[t]{2}{*}{ Gasperino et al. (2010) } & Cohort & US & $\begin{array}{l}16 \% \text { cases, } \\
5 \% \text { controls }\end{array}$ & $\begin{array}{l}20 \% \text { cases } \\
\text { IHM (cases) }\end{array}$ & 216,108 cases \\
\hline & & & & $\begin{array}{l}8 \% \text { IHM } \\
\text { (controls) }\end{array}$ & \\
\hline \multirow[t]{2}{*}{ Gravel et al. (2009) } & $\begin{array}{l}\text { Prospective } \\
\text { multicentre }\end{array}$ & Canada & $16.3 \%$ & - & 1430 \\
\hline & & & $5.7 \%$ attributable & & \\
\hline \multirow[t]{2}{*}{$\begin{array}{l}\text { Gulihar, Nixon, Jenkins } \\
\text { \& Taylor (2009) }\end{array}$} & Cohort & UK & $19 \%$ (cases) & $\begin{array}{l}67 \% \text { cases } \\
\text { at } 180 \text { days }\end{array}$ & 170 cases \\
\hline & & & $9 \%$ match cohort & $\begin{array}{l}29 \% \text { matched } \\
\text { cohort at } 180 \text { days }\end{array}$ & 3,247 matches \\
\hline Karas, Enoch \& Aliyu (2010) & Review & UK & Not applicable & Not applicable & Not applicable \\
\hline \multirow[t]{2}{*}{ Kenneally et al. (2007) } & Cohort & US & $36.7 \%$ & - & 278 \\
\hline & & & $6.1 \%$ attributable & & \\
\hline Labbe et al. (2008) & Cohort & Canada & $23.9 \%$ & - & 230 \\
\hline \multirow[t]{2}{*}{ Loo et al. (2005) } & $\begin{array}{l}\text { Prospective } \\
\text { multicentre }\end{array}$ & Canada & $24.8 \%$ & - & 1703 \\
\hline & & & $6.9 \%$ attributable & & \\
\hline Lyytikainen et al. (2009) & Cohort & Finland & - & $\begin{array}{l}14 \% \text { at } 30 \text { days } \\
\text { post-discharge }\end{array}$ & 8093 \\
\hline \multirow{2}{*}{$\begin{array}{l}\text { Marra, Edmond, Wenzel } \\
\text { \& Bearman (2007) }\end{array}$} & Cohort & US & & $17.2 \%$ at 14 days & 58 \\
\hline & & & & $27.6 \% 1 \mathrm{HM}$ & \\
\hline \multirow[t]{3}{*}{ McGowan et al. (2011) } & Cohort & UK & $35.5 \%$ & $13.4 \%$ at 7 days & 2,571 \\
\hline & & & & $20 \%$ at 14 days & \\
\hline & & & & $58.7 \%$ at 1 year & \\
\hline Musher et al. (2005) & $\begin{array}{l}\text { Prospective } \\
\text { observational }\end{array}$ & US & - & $27 \%$ at 90 days & 207 \\
\hline \multirow[t]{2}{*}{ Pant et al. (2010) } & Cohort & US & $13.6 \%$ & - & 184 \\
\hline & Cohort & UK & $24.7 \%$ & $30.0 \%$ at 90 days & 227 \\
\hline
\end{tabular}


Table 1 Summary of reported mortality from literature (Continued)

\begin{tabular}{|c|c|c|c|c|c|}
\hline \multicolumn{6}{|l|}{$\begin{array}{l}\text { Shears, Prtak } \\
\text { \& Duckworth (2010) }\end{array}$} \\
\hline \multirow[t]{2}{*}{ Sundram et al. (2009) } & Case control & UK & $\begin{array}{l}14.4 \% \text { at } 28 \text { days } \\
\text { (extrapolated) }\end{array}$ & $11 \%$ at 3 days (027) & 97 cases \\
\hline & & & & $3 \%$ at 3 days (106) & 97 controls \\
\hline Wilson et al. (2010) & Cohort & UK & $35.9 \%$ & - & 128 \\
\hline $\begin{array}{l}\text { Zilberberg, Shorr, } \\
\text { Micek, Doherty } \\
\text { \& Kollef (2009) }\end{array}$ & $\begin{array}{l}\text { Cohort. Secondary } \\
\text { analysis of } \\
\text { Kenneally et al. } \\
(2007)\end{array}$ & US & $26.9 \%<65$ years & - & 278 \\
\hline
\end{tabular}

$45.2 \%>65$

who died within 30 days (all-cause mortality) [14,15,1720,22,25-34].

The manner in which mortality was analysed and presented in the studies differed; however, there were some similarities. In several studies, participants were divided into those with CDI and those without [19,22,27,35]. Other studies divided participants into two groups: survivors and non-survivors $[18,26,33]$. Regardless of the methods used, similar data analysis involved using mortality at a fixed period. Commonly, $\mathrm{X}^{2}$, or Fisher's exact test, was used for categorical data analysis, while a $t$ test was used for continuous variables $[14,20]$. Kaplan-Meier survival analysis and regression model were used in some studies $[18,23,28,30,32,33]$. Not all studies undertook adjustment for variables when determining mortality rates. Despite collecting basic demographic data on cases, Charlson comorbidity data and exposure to recent medication such as antimicrobials, the study undertaken by Chung et al. [20] did not adjust for any variables in the calculation of hospital mortality and all-cause mortality.

In addition to studies comparing survivors and nonsurvivors, or those with and without CDI, some studies examined mortality by age group $[17,31,34]$. In the retrospective cohort study undertaken by McGowan et al. [31], age groups were divided into decades, with those under the age of 40 years grouped together. A significant difference in 30-day mortality was found for the three groups aged over 60 years, using $<60$ yeardsas the reference group $\left(X^{2}=65.82 ; \mathrm{df}: 2 ; \mathrm{P}<0.05\right)$. The study did not examine the effect of co-morbidity on outcome [31]. Similar to the work of McGowan et al. [31], a prospective multi-centred study of 1,430 participants demonstrated that age-specific mortality increased sharply after 60 years of age [17]. These two studies demonstrate the importance of collecting and analysing age-related data.

Some studies presented data that compared groups based on the causative strain of C.difficile [24,30,31]. The retrospective cohort study undertaken by Labbe et al. [30] found that patients affected by C.difficile ribotype 027 were twice as likely to die within 30 days of diagnosis than patients infected with other ribotypes. Similar results were demonstrated in a prospective case-controlled study comparing persons with CDI caused by ribotype 027, 106 and all other ribotypes [24].

\section{Discussion}

The majority of studies identified in this review were undertaken in the United States (nine), United Kingdom (seven) or Canada (three). No studies were included from an Asian or Asian Pacific setting. As there are different circulating strains of CDI in different countries, this is an important issue because mortality for persons with CDI in different regions may vary. A higher incidence of CDI compared to other countries with data on CDI incidence, coupled with an increased focus on CDI due to highprofile hospital outbreaks, may provide some insights into the number of included articles from these countries.

The majority of studies used the identification of toxins A or B via EIA or ELISA as part of the case definition of CDI. However, there were variations in which faecal samples were tested for C.difficile. The effect of such variations on reported mortality remains unknown. However, it would be logical to assume that a less sensitive laboratory detection approach may identify fewer cases in a given population. This has the potential to underestimate the incidence of CDI and, thus, the total number of people who died after having CDI. The argument for a standardised testing approach for CDI has previously been made [36].

A co-morbidity score, such as the Charlson co-morbidity index, was collected in a limited number of studies [18$21,23,30,33,35]$. A number of studies used other tools such as the American Society of Anaesthesiologists (ASA) grade or Acute Physiology and Chronic Health Evaluation (APACHE) II, while a number of studies collected data on comorbidities but did not specify how or why they chose those co-morbidities [14,17,24,27,28,34,37]). The admitting diagnosis was collected for two studies $[19,23]$. The variation in the use of co-morbidity data makes comparisons between studies challenging and potentially limits the validity of results. Where co-morbidities were collected, they 
were shown to influence mortality in patients with CDI $[18,27]$. In one instance where co-morbidity data were not collected, the researchers recognised this limitation and suggested that this area be included in future research [31].

The manner in which data were collected about drug therapy, surgery and nasogastric tube exposure were not reported consistently, with different periods and a range of procedures used. Further, in these studies, mortality was one outcome being examined alongside other variables such as risk factors for CDI. If a study was to examine CDI mortality as the single outcome, then the usefulness of including data on some of the data described above could be limited, particularly as there is no standardised method or definition used.

\section{Conclusion}

There was limited homogeneity between the studies included in this review. Differences in study design, patient groups and data collected from participants were found. Some studies lacked demographic and co-morbidity data, which is a similar finding to the review undertaken by Karas, Enoch and Aliyu [13]. In general, all-cause 30-day mortality appeared to be high, with 15 studies indicating a mortality of $15 \%$ or more. Several studies demonstrated that increased age was a risk factor for mortality, indicating the need to include and analyse such data in future studies.

No articles from an Asian or Asian Pacific setting were included in this review. Even accepting all-cause mortality at the low end of the included studies in this review, CDI clearly have a significant effect on hospitalised patients. Studies investigating the mortality of CDI in settings outside of Europe and North America are needed so that the epidemiology of CDI in these regions can be understood.

Future studies examining the mortality of CDI should include basic demographic data, reporting of mortality at seven days, 30 days and 90 days after the first diagnosis of the CDI, the use of exclusion criteria and acquisition definitions as recommended in the international literature. In addition, the studies should use a co-morbidity index score such as the Charlson co-morbidity index. In doing so, pooling data becomes possible and comparisons between studies become easier. Similarly, the addition of data on antibiotic exposure will assist future meta-analysis on the role of antibiotics in CDI. The recommendations posed for future studies are similar to those described by Karas, Enoch and Aliyu [13] in the only review article identified. This review supports the notion that measures to prevent CDI are needed, given its impact on mortality.

\section{Competing interest}

No conflict was declared by the authors for the study itself.

\section{Authors' contributions}

$\mathrm{BM}$ and $\mathrm{AG}$ were responsible for the study concept and design. BM performed data collection. BM and AG were responsible for data analysis and the draft of the manuscript. All authors have read and approved the manuscript.

\section{Acknowledgments}

BM acknowledges the Rosemary Norman Foundation and the Nurses Memorial Centre through the award of the "Babe" Norman scholarship for financial support to enable PhD studies.

Additional financial support for this research has been provided by The Medical Advances Without Animals Trust, the Royal College of Nursing Australia and the Tasmanian Florence Nightingale Grants and Awards Trust. The views expressed in this paper are the authors' alone. Funders played no role in the conduct of this research.

BM wishes to thank the peer reviewers of this article for their feedback.

\section{Author details}

${ }^{1}$ School of Nursing, Midwifery and Paramedicine, Australian Catholic University, DicksonPO BOX 256, ACT, Australia. ${ }^{2}$ Research Associate, National Centre for Clinical Outcomes Research (NaCCOR), Australian Catholic University, Sydney, Australia.

Received: 2 February 2012 Accepted: 12 May 2012

Published: 30 May 2012

\section{References}

1. McDonald LC, Coignard B, Dubberke E, Song X, Horan T, Kutty PK, Ad Hoc Clostridium difficile Surveillance Working G: Recommendations for surveillance of Clostridium difficile-associated disease. Infect Contr Hosp Epidemiol 2007, 28:140-145.

2. Stuart R, Marshall C: Clostridium difficile infection: a new threat on our doorstep. Med J Aust 2011, 194:331-332.

3. Van Gessel H, Riley T, McGregor A: Clostridium difficile infection: an update for infection control practitioners. Healthc Infect 2009, 14:115-118.

4. Heinlen L, Ballard JD: Clostridium difficile infection. Am J Med Sci 2010, 340:247-252.

5. Khanna S, Pardi DS: The growing incidence and severity of Clostridium difficile infection in inpatient and outpatient settings. Expert Rev Gastroenterol Hepatol 2010, 4:409-416.

6. Cartman ST, Heap JT, Kuehne SA, Cockayne A, Minton NP: The emergence of 'hypervirulence' in Clostridium difficile. Int J Med Microbiol 2010, 300:387-395.

7. Healthcare Commission: Investigation into outbreaks of Clostridium difficile at Stoke Mandeville Hospital, Buckinghamshire Hospitals NHS Trust. In Book Investigation into outbreaks of Clostridium difficile at Stoke Mandeville Hospital, Buckinghamshire Hospitals NHS Trust. Edited by. City: Commission for Healthcare Audit and Inspection; 2006.

8. Healthcare Commission: Investigation into outbreaks of Clostridium difficile at Maidstone and Tunbridge Wells NHS Trust. In Book Investigation into outbreaks of Clostridium difficile at Maidstone and Tunbridge Wells NHS Trust. Edited by. City: Commission for Healthcare Audit and Inspection; 2007.

9. Healthcare Inspectorate Wales: Special Review of the Outbreak of Clostridium difficile at the former North Glamorgan NHS Trust (now part of Cwm Taf NHS Trust) between March and April 2008. In Book Special Review of the Outbreak of Clostridium difficile at the former North Glamorgan NHS Trust (now part of Cwm Taf NHS Trust) between March and April 2008. Edited by. City: Healthcare Inspectorate Wales; 2009.

10. Kelly CP, LaMont JT: Clostridium difficile-more difficult than ever. N Engl J Med 2008, 359:1932-1940.

11. Whittemore $R$, Knafl $K$ : The integrative review: updated methodology. $J$ Adv Nurs 2005, 52:546-553.

12. Lyytikainen $\mathrm{O}$, Turunen $\mathrm{H}$, Sund R, Rasinpera M, Kononen E, Ruutu P, Keskimaki I: Hospitalizations and deaths associated with Clostridium difficile infection, Finland, 1996-2004. Emerg Infect Dis 2009, 15:761-765.

13. Karas JA, Enoch DA, Aliyu SH: A review of mortality due to Clostridium difficile infection. J Infect 2010, 61:1-8.

14. Cadena J, Thompson GR 3rd, Patterson JE, Nakashima B, Owens A, Echevarria K, Mortensen EM: Clinical predictors and risk factors for relapsing Clostridium difficile infection. Am J Med Sci 2010, 339:350-355.

15. Shears P, Prtak L, Duckworth R: Hospital-based epidemiology: a strategy for 'dealing with Clostridium difficile'. J Hosp Infect 2010, 74:319-325. 
16. Musher DM, Aslam S, Logan N, Nallacheru S, Bhaila I, Borchert F, Hamill RJ: Relatively poor outcome after treatment of Clostridium difficile colitis with metronidazole. Clin Infect Dis 2005, 40:1586-1590.

17. Gravel D, Miller M, Simor A, Taylor G, Gardam M, McGeer A, Hutchinson J, Moore D, Kelly S, Boyd D, et al: Health care-associated Clostridium difficile infection in adults admitted to acute care hospitals in Canada: a Canadian Nosocomial Infection Surveillance Program Study. Clin Infect Dis 2009, 48:568-576.

18. Kenneally C, Rosini JM, Skrupky LP, Doherty JA, Hollands JM, Martinez E, McKinzie WE, Murphy T, Smith JR, Micek ST, Kollef MH: Analysis of 30-day mortality for clostridium difficile-associated disease in the ICU setting. [Erratum appears in Chest. Nov;132(5):1721 Note: McKenzie, Wendi [corrected to McKinzie, Wendi E]]. Chest 2007, 2007(132):418-424.

19. Loo VG, Poirier L, Miller MA, Oughton M, Libman MD, Michaud S, Bourgault AM, Nguyen T, Frenette C, Kelly M, et al: A predominantly clonal multiinstitutional outbreak of Clostridium difficile-associated diarrhea with high morbidity and mortality. N Engl J Med 2005, 353:2442-2449.

20. Chung C-H, Wu C-J, Lee H-C, Yan J-J, Chang C-M, Lee N-Y, Chen P-L, Lee C-C, Hung Y-P, Ko W-C: Clostridium difficile infection at a medical center in southern Taiwan: incidence, clinical features and prognosis. J Microbiol Immunol Infect 2010, 43:119-125.

21. Cloud J, Noddin L, Pressman A, Hu M, Kelly C: Clostridium difficile strain NAP-1 is not associated with severe disease in a nonepidemic setting Clin Gastroenterol Hepatol 2009, 7:868-873. e862.

22. Gasperino J, Garala M, Cohen HW, Kvetan V, Currie B: Investigation of critical care unit utilization and mortality in patients infected with Clostridium difficile. J Crit Care 2010, 25:282-286.

23. Marra AR, Edmond MB, Wenzel RP, Bearman GML: Hospital-acquired Clostridium difficile-associated disease in the intensive care unit setting: epidemiology, clinical course and outcome. BMC Infect Dis 2007, 7:42.

24. Sundram F, Guyot A, Carboo I, Green S, Lilaonitkul M, Scourfield A: Clostridium difficile ribotypes 027 and 106: clinical outcomes and risk factors. J Hosp Infect 2009, 72:111-118.

25. Arvand M, Hauri AM, Zaiss NH, Witte W, Bettge-Weller G: Clostridium difficile ribotypes 001, 017, and 027 are associated with lethal $C$. difficile infection in Hesse, Germany. Euro Surveill 2009, 14.

26. Bhangu S, Bhangu A, Nightingale $P$, Michael A: Mortality and risk stratification in patients with Clostridium difficile-associated diarrhoea. Colorectal Dis 2010, 12:241-246.

27. Bishara J, Peled N, Pitlik S, Samra Z: Mortality of patients with antibioticassociated diarrhoea: the impact of Clostridium difficile. J Hosp Infect 2008, 68:308-314.

28. Fenner $L$, Frei $R$, Gregory M, Dangel M, Stranden A, Widmer AF: Epidemiology of Clostridium difficile-associated disease at University Hospital Basel including molecular characterisation of the isolates 2006-2007. Eur J Clin Microbiol Infect Dis 2008, 27:1201-1207.

29. Gulihar A, Nixon M, Jenkins D, Taylor GJ: Clostridium difficile in hip fracture patients: prevention, treatment and associated mortality. Injury 2009, 40:746-751

30. Labbe A-C, Poirier L, Maccannell D, Louie T, Savoie M, Beliveau C, Laverdiere M, Pepin J: Clostridium difficile infections in a Canadian tertiary care hospital before and during a regional epidemic associated with the BI/NAP1/027 strain. Antimicrob Agents Chemother 2008, 52:3180-3187.

31. McGowan AP, Lalayiannis LC, Sarma JB, Marshall B, Martin KE, Welfare MR: Thirty-day mortality of Clostridium difficile infection in a UK National Health Service Foundation Trust between 2002 and 2008. J Hosp Infect 2011, 77:11-15.

32. Pant C, Madonia P, Minocha A, Manas K, Jordan P, Bass P: Laboratory markers as predictors of mortality in patients with Clostridium difficile infection. J Investig Med 2010, 58:43-45.

33. Wilson V, Cheek L, Satta G, Walker-Bone K, Cubbon M, Citron D, Gerding DN, Llewelyn MJ: Predictors of death after Clostridium difficile infection: a report on 128 strain-typed cases from a teaching hospital in the United Kingdom. Clin Infect Dis 2010, 50:e77-e81.

34. Zilberberg MD, Shorr AF, Micek ST, Doherty JA, Kollef MH: Clostridium difficile-associated disease and mortality among the elderly critically ill. Crit Care Med 2009, 37:2583-2589.

35. Dubberke ER, Butler AM, Reske KA, Agniel D, Olsen MA, D'Angelo G, McDonald LC, Fraser VJ: Attributable outcomes of endemic Clostridium difficile-associated disease in nonsurgical patients. Emerg Infect Dis 2008, 14:1031-1038
36. Mitchell B, Ware C, McGregor A, Brown S, Wells A: Clostridium difficile infection in Tasmanian public hospitals 2006-2010. Healthc Infect 2011, 16:101-106

37. Goorhuis A, Van der Kooi T, Vaessen N, Dekker FW, Van den Berg R, Harmanus C, van den Hof S, Notermans DW, Kuijper EJ: Spread and epidemiology of Clostridium difficile polymerase chain reaction ribotype 027/toxinotype III in The Netherlands. Clin Infect Dis 2007, 45:695-703.

doi:10.1186/2047-2994-1-20

Cite this article as: Mitchell and Gardner: Mortality and Clostridium difficile infection: a review. Antimicrobial Resistance and Infection Control 2012 1:20.

\section{Submit your next manuscript to BioMed Central and take full advantage of:}

- Convenient online submission

- Thorough peer review

- No space constraints or color figure charges

- Immediate publication on acceptance

- Inclusion in PubMed, CAS, Scopus and Google Scholar

- Research which is freely available for redistribution 